Faculty of Science

Faculty Publications

This is a post-review version of the following article:

Mass transfer and convection effects in small-scale catalytic hydrogenation Jingwei Luo, Yang Wu, Harmen S. Zijlstra, David A. Harrington and J. Scott McIndoe

June 2017

The final published version of this article can be found at:

https://doi.org/10.1039/C7CY00492C

Citation for this paper:

Luo, J., Wu, Y., Zijlstra, H.S., Harrington, D.A. \& McIndoe, J.S. (2017). Mass transfer and convection effects in small-scale catalytic hydrogenation. Catalysis Science \& Technology, 12(7), 2609-2615. https://doi.org/10.1039/C7CY00492C 


\title{
Mass transfer and convection effects in small-scale catalytic hydrogenation
}

Jingwei Luo, Yang Wu, Harmen S. Zijlstra, David A. Harrington* and J. Scott McIndoe*

Department of Chemistry, University of Victoria, P.O. Box 3065 Victoria, BC V8W3V6, Canada.

Fax:+1 (250)721-7147; Tel:+1 (250)721-7181; E-mail:_harr@uvic.ca, mcindoe@uvic.ca

\begin{abstract}
Keywords

Diffusion, convection, hydrogenation, mass spectrometry, real-time analysis, interfacial mass transfer
\end{abstract}

\section{Graphical abstract}
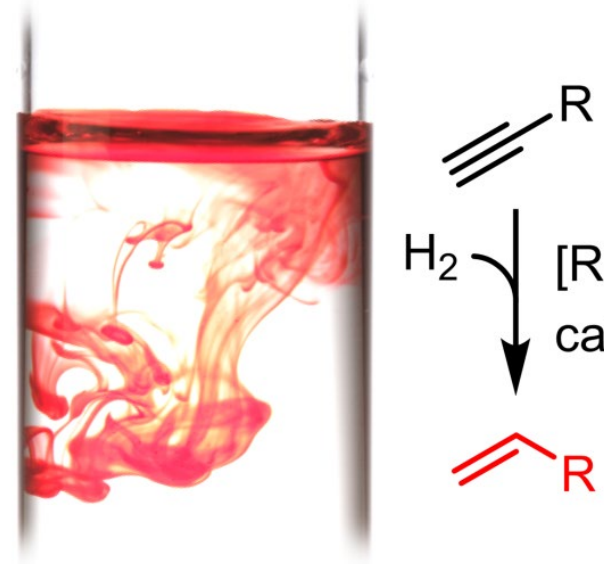

$\mathrm{H}_{2} \searrow \begin{aligned} & {[\mathrm{Rh}]^{+}} \\ & \text {catalyst }\end{aligned}$

Introduction

Catalytic reactions involving a gas as a reactant are inherently more complicated than homogeneous systems in which all components are in a single phase. Efficient transfer of the gas 
to the solution requires sufficient interfacial surface area as well as stirring to ensure good mixing within the solution. Jordan generalizes gas absorption into a liquid as occurring with halftimes of several tens of seconds for a typical reactor at moderate mixing rates. ${ }^{1}$ Transport effects in homogeneous catalysis have been reviewed. ${ }^{2}$ Gas-liquid mass transfer has most often been measured via pressure drop (the so-called dynamic method), ${ }^{3}$ and has been applied in catalytic work in the context of acetylene absorption by aqueous cuprous chloride solutions. ${ }^{4}$ The maximum gas-liquid mass transfer rate can be compared with the maximum reaction rate to see if mass transfer resistance is likely to be limiting. Unless the rate of gas-liquid transfer is much faster than the reaction rate, the concentration of the dissolved gas will be lowered and the reaction will be correspondingly slowed.

Chemists using sensitive modern spectroscopic methods often perform reactions at low pressures in small reaction vessels on relatively short time scales. Under such circumstances, dissolution of the gas into solution may become turnover limiting, or at least complicate the observed kinetics. This is particularly problematic in cases where vials are used as reaction vessels, and becomes extreme when these reactors become especially long with small cross sections, as is the case for NMR tubes. ${ }^{5}$ Precautions such as mechanical mixers ${ }^{6}$ or high pressure bubble column reactors ${ }^{7}$ are required to ensure that the kinetics of the reaction rather than that of mass transfer are being studied.

Our research focuses on the development of real time monitoring of catalytic reactions to solve mechanistic problems in organometallic chemistry, with an emphasis on electrospray ionization mass spectrometry (ESI-MS). ${ }^{8}$ We use this technique in conjunction with the simple, lowvolume method of pressurized sample infusion (PSI - essentially a cannula transfer of a reacting solution through capillary tubing to the mass spectometer). ${ }^{9}$ Though PSI-ESI-MS is usually employed for the study of reactions at low concentrations, it is still feasible that for reactions with gases of low solubility, transfer of the reacting gas into solution could become rate limiting. We had not encountered this limit in previous experiments, ${ }^{10}$ because we were dealing with solutions with large surface areas that were vigorously stirred (typically Schlenk flasks), and the reactions were relatively slow. However, these effects become important when performed in small vials, and such vessels are attractive when carrying out many simultaneous reactions.

Because ESI-MS operates by transfer of charged species from solution into the gas phase, charged tags must be used in order to monitor reactions. We typically employ substrates decorated peripherally with $\left[-\mathrm{CH}_{2} \mathrm{PPh}_{3}\right]^{+}\left[\mathrm{PF}_{6}\right]^{-}$, ${ }^{11}$ which is very "electrospray-active" by virtue of (a) its bulk (and hence high surface activity) and (b) by the use of a non-coordinating ion (discouraging the formation of ion pairs). ${ }^{12}$ To examine the effects of the rate of mass transport 
into solution, the reaction we chose to study was one we have already looked at in some detail in conventional Schlenk vessels: the selective hydrogenation of a charge-tagged alkyne in fluorobenzene using a cationic rhodium catalyst. ${ }^{13}$ This reaction continues to be of interest in its enantioselective version, ${ }^{14}$ as hydrogenation of prochiral substrates by a chiral catalyst leads to the addition of considerable value. ${ }^{15}$

Hydrogen is not especially soluble in organic solvents. At $25^{\circ} \mathrm{C}$, its mole fraction solubility is $\sim 1.5 \times 10^{-4}$ for dimethylformamide, acetonitrile and dioxane; $\sim 3 \times 10^{-4}$ for acetone, toluene and tetrahydrofuran, and $\sim 7 \times 10^{-4}$ for $n$-alkanes. ${ }^{16}$ Data could not be found for fluorobenzene, but the Henry's law constant for $\mathrm{H}_{2}$ in fluorobenzene has been estimated as $\ln \left(K_{\mathrm{H}}\right)=7.89,{ }^{17}$ from which the mol fraction solubility at 1 atm and $25^{\circ} \mathrm{C}$ is $3.74 \times 10^{-4}$.

We here investigate the point at which gas-solution mass transport becomes important in low pressure reactions, by measuring the rate of hydrogenation of an alkyne under conditions where we varied the surface area of the solution, the concentration of hydrogen, and the stirring rate.

\section{Experimental}

All reactions were carried out under an argon atmosphere. Fluorobenzene was purchased from Oakwood Chemicals and freshly distilled from $\mathrm{CaH}_{2}$ before use. 99.9995\% pure hydrogen was purchased from Airgas. The charged alkyne was prepared by a previously published method. ${ }^{13}$ The rhodium catalyst, $\left[\mathrm{Rh}\left(\mathrm{P}^{c} \mathrm{Pr}_{3}\right)_{2}\left(\eta^{6}-\mathrm{PhF}\right)\right]^{+}\left[\mathrm{B}\left\{3,5-\left(\mathrm{CF}_{3}\right)_{2} \mathrm{C}_{6} \mathrm{H}_{3}\right\}_{4}\right]^{-} \quad\left(\mathrm{P}^{c} \mathrm{Pr}_{3}=\right.$ triscyclopropylphosphine, $\mathrm{PhF}=$ fluorobenzene) was prepared by the method of Goldman et al. ${ }^{18}$ All mass spectra were collected by using a Micromass Q-Tof micro mass spectrometer with 5 second scans in positive ion mode using pneumatically assisted electrospray ionization: capillary voltage: $3000 \mathrm{~V}$; extraction voltage: $0.5 \mathrm{~V}$; source temperature: $90^{\circ} \mathrm{C}$; desolvation temperature: $180^{\circ} \mathrm{C}$; cone gas flow: $100 \mathrm{~L} / \mathrm{h}$; desolvation gas flow: $100 \mathrm{~L} / \mathrm{h}$; collision voltage: $2 \mathrm{~V}$ (for MS experiments); MCP voltage: $2400 \mathrm{~V}$.

ESI-MS reaction monitoring using pressurized sample infusion. ${ }^{19}$ A fluorobenzene solution (8.0-9.0 ml) of $\left[\mathrm{Ph}_{3} \mathrm{P}\left(\mathrm{CH}_{2}\right)_{4} \mathrm{C}_{2} \mathrm{H}\right]^{+}\left[\mathrm{PF}_{6}\right]^{-}(3.1 \mathrm{mg}, 64 \mu \mathrm{mol})$ was monitored using a PSI-ESI-MS setup. The vial was pressurized to 3 psi using 99.99\% purity argon. At 3 psi and a capillary length of $0.6 \mathrm{~m}$ and an internal diameter of $125 \mu \mathrm{m}$, the flow rate is approximately $40 \pm 20 \mu \mathrm{L}$ $\min ^{-1},{ }^{19 b}$ meaning that the solution spends about 12 seconds in the capillary, and the effect of this time has been regarded as negligible in terms of the reactivity. $\left[\mathrm{Rh}\left(\mathrm{P}^{\mathrm{C}} \mathrm{Pr}_{3}\right)_{2}(\mathrm{PhF})\right]^{+}\left[\mathrm{BAr}{ }_{4}^{\mathrm{F}}\right]^{-}(8.7$ to $17.4 \mathrm{mg}, 6.4 \mu \mathrm{mol}$ to $12.8 \mu \mathrm{mol}, 10 \%$ to $20 \%$ catalyst loading) was dissolved in 1 to $2 \mathrm{~mL}$ of $\mathrm{PhF}$ and injected into the well-stirred vial via a septum. $1.4 \mathrm{ml}$ of $\mathrm{H}_{2}(63 \mu \mathrm{mol})$ was injected via 
gas-tight syringe to start the reaction. The solution end of the PEEK tubing was protected with a filter. Data were processed by normalizing the abundance of each species to the total ion count of all charge tagged species. No smoothing of the data was performed. The amount of hydrogen injected was doubled for the reactions involving two equivalents of hydrogen. Stirring rate was either $240 \mathrm{rpm}$ or $0 \mathrm{rpm}$.

Data fitting. To fit the data, the known analytical solution for the concentration of product vs time in the 2-step reaction (Eq. (28) of Ref. 20), was modified to have area and volumedependent rate constants using Eq. (7). An expression for the sum of squares of the deviations of the data from the model was found for each vial using the known volumes and interfacial surface areas of each vial. The global sum of squares was found by adding the sums of squares for the four vials. This function was then minimized numerically to find the unknown parameters $k_{\mathrm{f}}, k_{\mathrm{b}}$ and $k^{\prime}$. The manipulations of the equations were carried out in the symbolic algebra program Maple (Maplesoft, a division of Waterloo Maple Inc., Waterloo, Ontario, www.maplesoft.com), and the minimization used the default procedure of the DirectSearch package for Maple, available at http://www.maplesoft.com/applications/view.aspx?SID=101333.

\section{Results and discussion}

Four reaction flasks with approximately the same volume $(20 \pm 3 \mathrm{ml})$ but with increasing internal cross-sectional area: $\mathrm{V} 1=1.3 \mathrm{~cm}^{2}, \mathrm{~V} 2=2.8 \mathrm{~cm}^{2}, \mathrm{~V} 3=5.3 \mathrm{~cm}^{2}$ and $\mathrm{V} 4=10.8 \mathrm{~cm}^{2}$ (these values were chosen as they matched standard glass tubing sizes) were used in all experiments (Figure 1). Necks were designed to be used with rubber septa. 


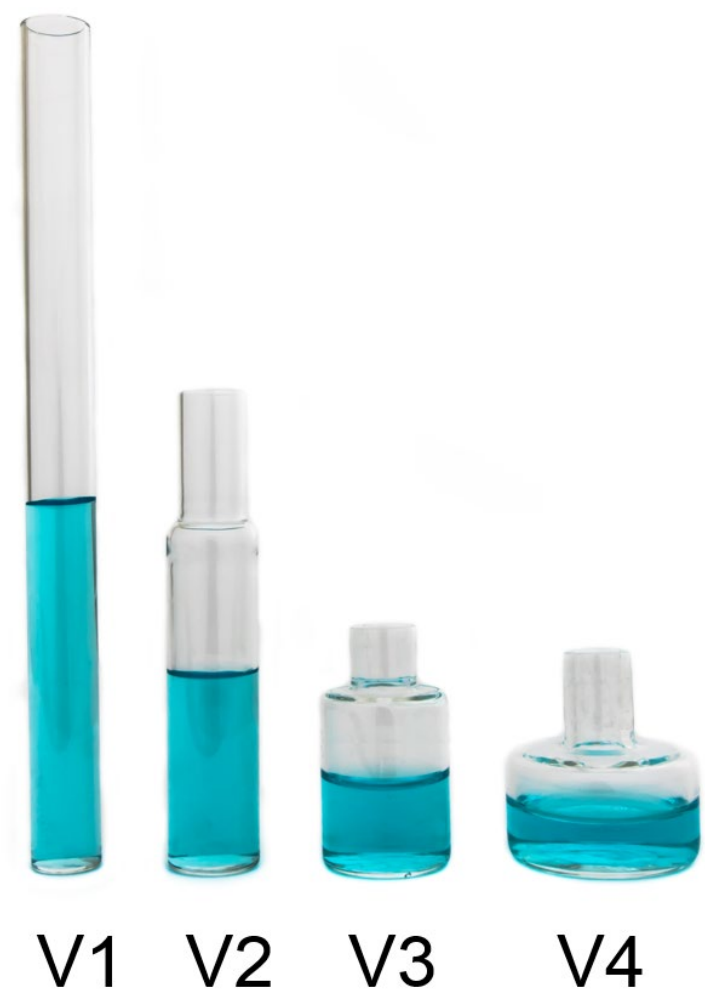

Figure 1. The four reaction flasks. Nominal interfacial surface areas: $\mathrm{V} 1=1.3 \mathrm{~cm}^{2}, \mathrm{~V} 2=2.8 \mathrm{~cm}^{2}, \mathrm{~V} 3=5.3 \mathrm{~cm}^{2}$ and $\mathrm{V} 4=10.8 \mathrm{~cm}^{2}$

Exact volumes, taking into account septum and stir bar, were V1 $=21.2 \mathrm{ml}, \mathrm{V} 2=19.6 \mathrm{ml}, \mathrm{V} 3=$ $17.6 \mathrm{ml}$, and V4 $=22.9 \mathrm{ml}$. Solvent $(8$ or $9 \mathrm{ml}$ ), catalyst and alkyne were added, the vials fitted with septa, pressurized with argon and the reaction initiated by injection of one or two equivalents of hydrogen. Figure 2 shows the comparison of hydrogenation in stirred vials with 4 different surface areas. If surface area had no effect on the overall rate of reaction, all traces should overlay each other, but that is definitely not the case. If the surface area is small (V1, dark blue/blue and V2, dark green/green), the reaction is obviously slowed, but when the surface area is larger, this effect is less pronounced as V3 (red/pink) and V4 (brown/orange) have similar rates. The stirring speed of $240 \mathrm{rpm}$ was slow (more typically reactions are stirred at $>500 \mathrm{rpm}$ ) to ensure that the surface was not visibly deformed during the stirring process (to prevent the interfacial area from changing). 


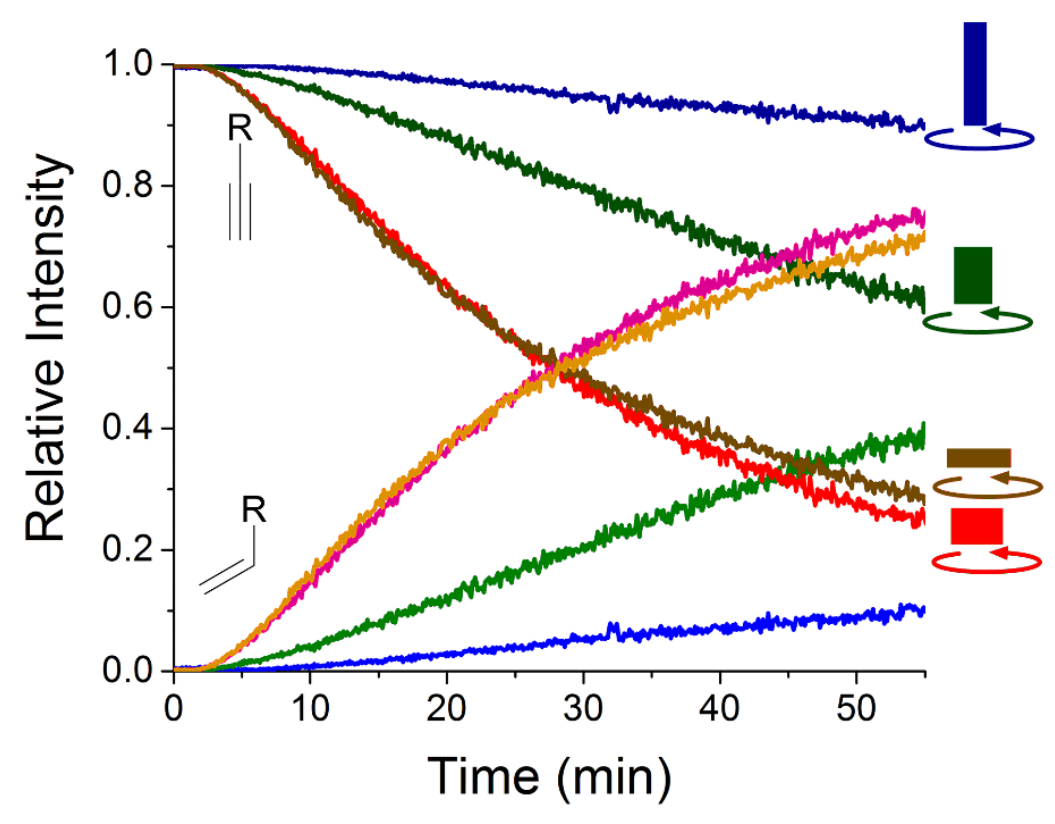

Figure 2. Comparison of 4 vials with $10 \%$ catalyst loading: alkyne hydrogenation with 1 equivalent of hydrogen at the same stir speed $(240 \mathrm{rpm})$ at room temperature $\left(22^{\circ} \mathrm{C}\right)$. The rectangular icons show the shape of the vial used, circulating arrow indicates reaction was stirred. This notation will be used throughout.

We investigated the exact same reactions but this time in unstirred vials (Figure 3), to probe solution mixing effects. The reaction is substantially slower for the lowest diameter vials, whereas the lack of stirring has almost no effect on the reaction rate in the vessel with the largest surface area - as expected, mixing is less efficient in elongated vessels. Interestingly, the data is less smooth for the unstirred reactions - note the irregular fluctuations in slope changes for the V4 data, and hints of similar behavior for V3. This phenomenon will be discussed later, in the experiments where two equivalents of hydrogen were employed. 


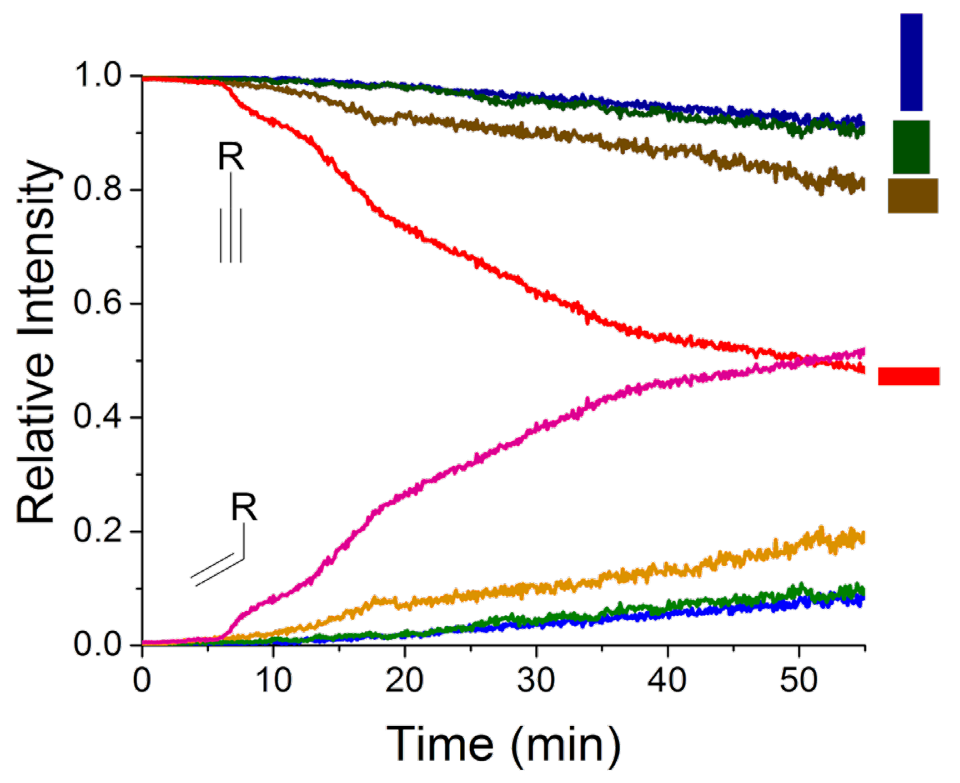

Figure 3. Comparison of 4 vials with $10 \%$ catalyst loading: alkyne hydrogenation with 1 equivalent of hydrogen at the same stir speed $(0 \mathrm{rpm})$ at room temperature $\left(22{ }^{\circ} \mathrm{C}\right)$.

Figure 4 examines the effect of stirring for the four different shapes of flask. For the smallest surface area vial, V1, whether stirring is on or off makes very little difference to the observed rate of reaction. Careful inspection reveals an apparent induction period of about 5 minutes, regardless of whether the solution is stirred or not. It seems that stirring does not effectively mix the solution in this particular shape of flask. In contrast, stirring of flask V2 does make a considerable difference to the rate, suggesting effective mixing of the solution at the gas/liquid interface with the bulk solution when stirred. A similar improvement in rate is noted for V3. V4, however, showed only a modest increase in rate upon stirring, suggesting that the contact area is sufficiently large that the reaction is partly controlled by the rate of the reaction in solution. 

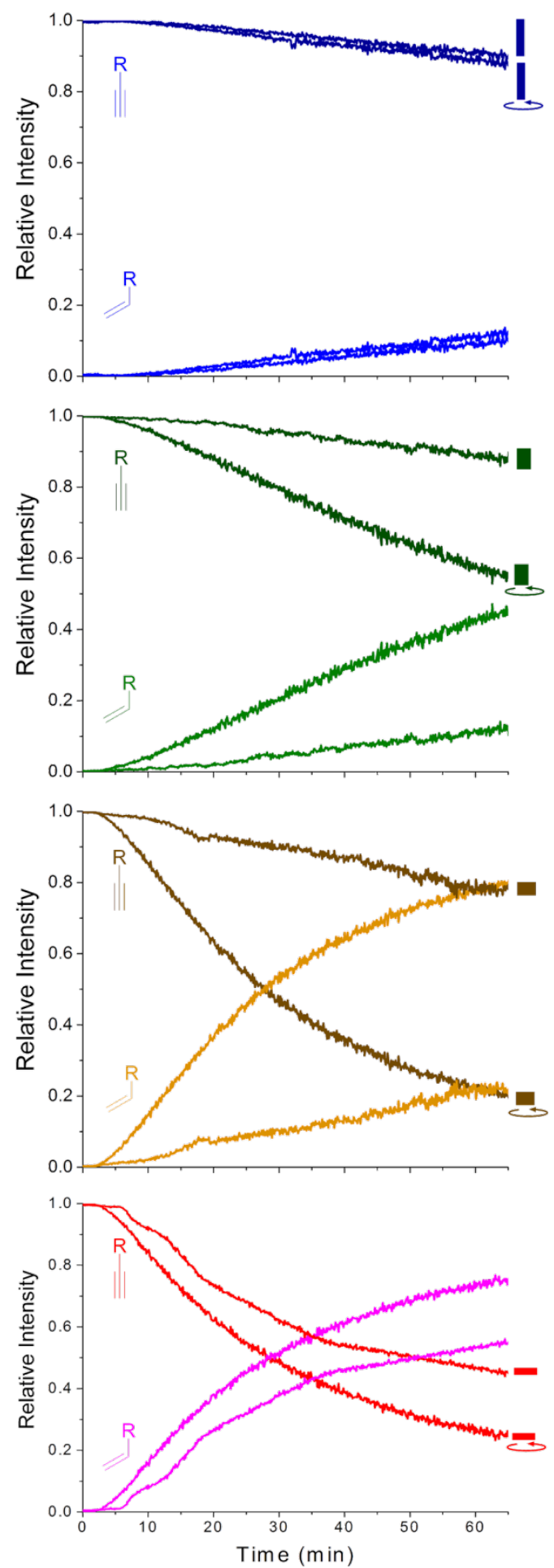

Figure 4. $10 \%$ catalyst loading, 1 equivalent of $\mathrm{H}_{2}$, with (arrow) and without stirring. From top to bottom: V1, V2, V3, V4. 
Mass transfer effects can be further probed by changing the catalyst concentration (with the assumption that the rate is first order in catalyst, the rate should be proportional to catalyst concentration as long as mass transfer is not rate-limiting. ${ }^{1}$ We repeated the V3 and V4 experiments with twice the catalyst loading ( $20 \%$ vs. $10 \%$, see Figure 5). For V4, the reaction approached the anticipated doubling in rate in the early stages. However, for V3, the rate was only slightly faster with $20 \%$ catalyst loading compared to $10 \%$.
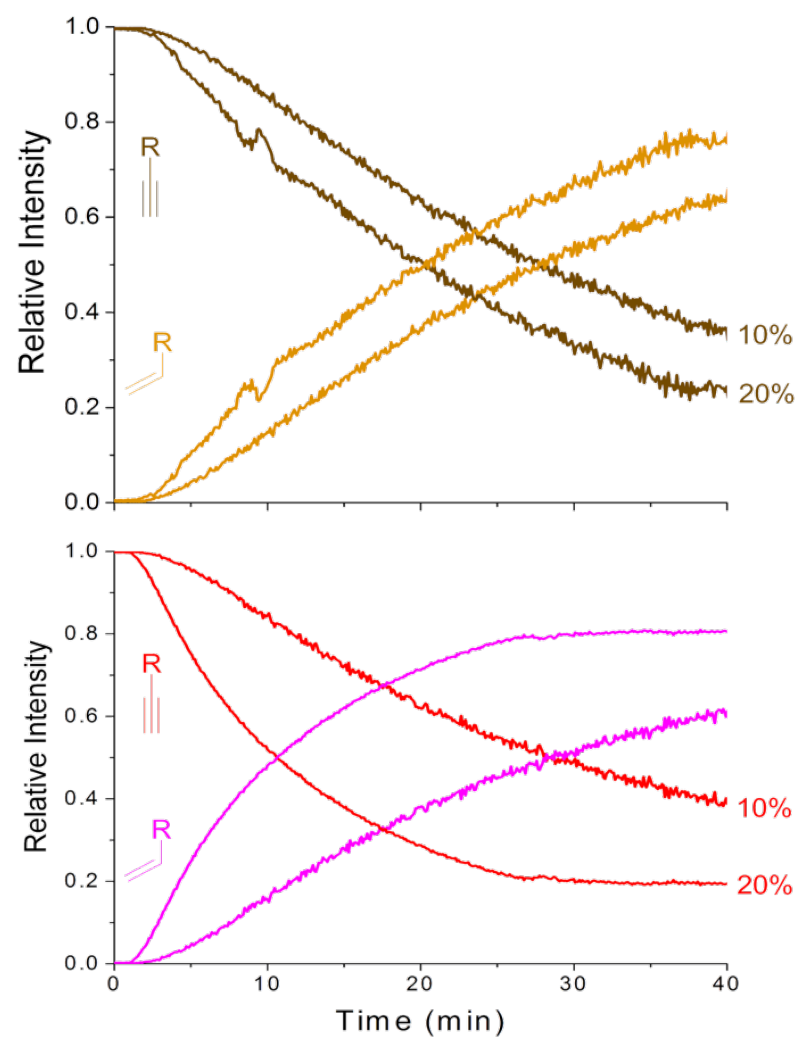

Figure 5. $10 \%$ catalyst loading vs. $20 \%$ catalyst loading for $\mathrm{V} 3$ (top) and $\mathrm{V} 4$ (bottom). 1 equivalent of $\mathrm{H}_{2}$, stirred reaction.

We repeated the stirred reactions using 2 equivalents of hydrogen. The reaction was approximately twice as fast as the same reaction with one equivalent of $\mathrm{H}_{2}$, as predicted by the model discussed below, in which both the mass transfer across the interface and the reaction in solution are first order in hydrogen (Figure 6). ${ }^{13}$ 

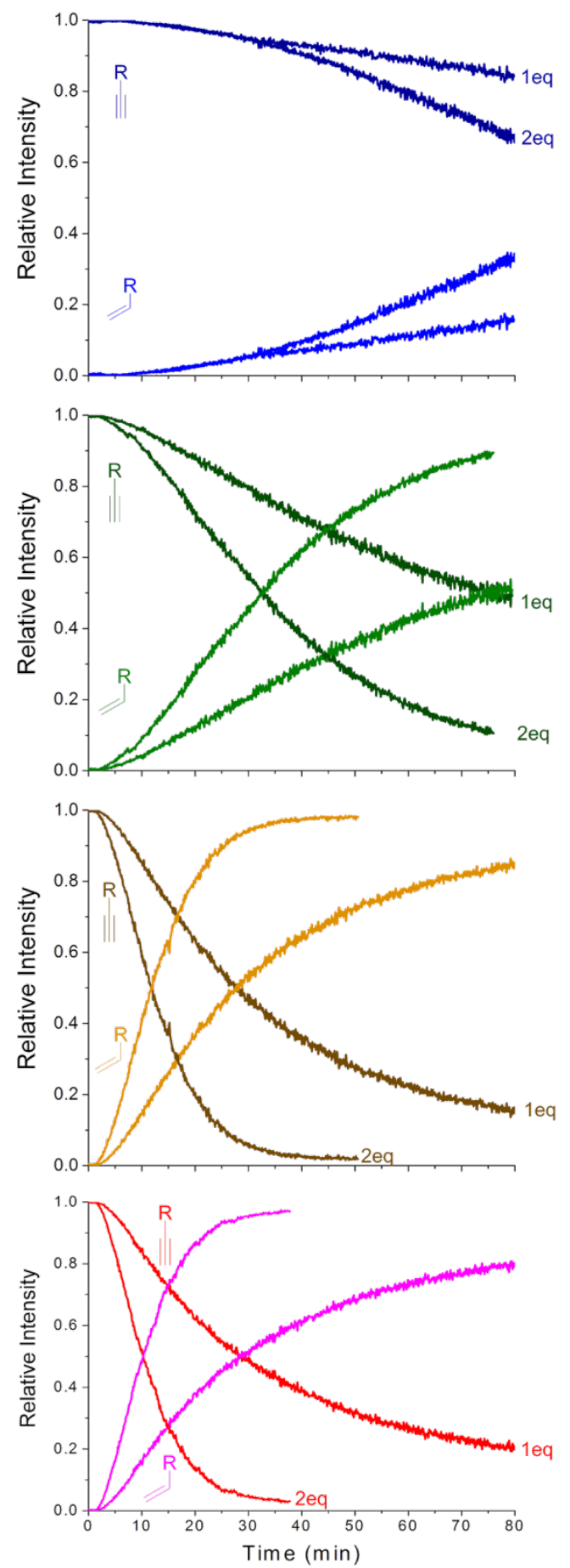

Figure 6. Reactions with 1 and 2 equivalents of $\mathrm{H}_{2}$, at $10 \%$ catalyst loading. From top to bottom: V1, V2, V3 and V4. 
Another set of experiments used two equivalents of hydrogen, $10 \%$ catalyst loading and examined the effects of stirring (Figure 7). As expected, the reactions are faster in the stirred vessels. The profiles for the unstirred vessels are unexpectedly erratic and not chemically reasonable in some cases. For V3 nothing at all appears to happen for about 8 minutes, then the reaction proceeds to/for $\sim 20 \%$, after which it retreats to $0 \%$ conversion before behaving more normally (though never attaining a smooth curve of the type seen in all stirred reactions). We can account for the erratic behavior of the unstirred reactions with two equivalents of $\mathrm{H}_{2}$ by invoking convection effects. As the solutions are not being actively mixed, injection of $\mathrm{H}_{2}$ will rapidly hydrogenate the alkyne near the interface, which will only slowly move through the solution by convection (induced by the exotherm created as hydrogenation occurs at the surface, or simply residual circulation induced by the perturbation due to the injection and/or by the flow from the solution into the capillary). The sampling method examines a single point in solution, not the average of the whole, so it can reveal heterogeneities in solution composition (Figure 8). At the same instant, differences in the sampling point (1-6) in solution will produce different concentration measurements if the solution is not homogeneous (not well stirred). The fluctuations are present but smaller for unstirred solutions with lower catalyst concentrations, because the slower response of the reaction to the fluctuations tends to average them out. 

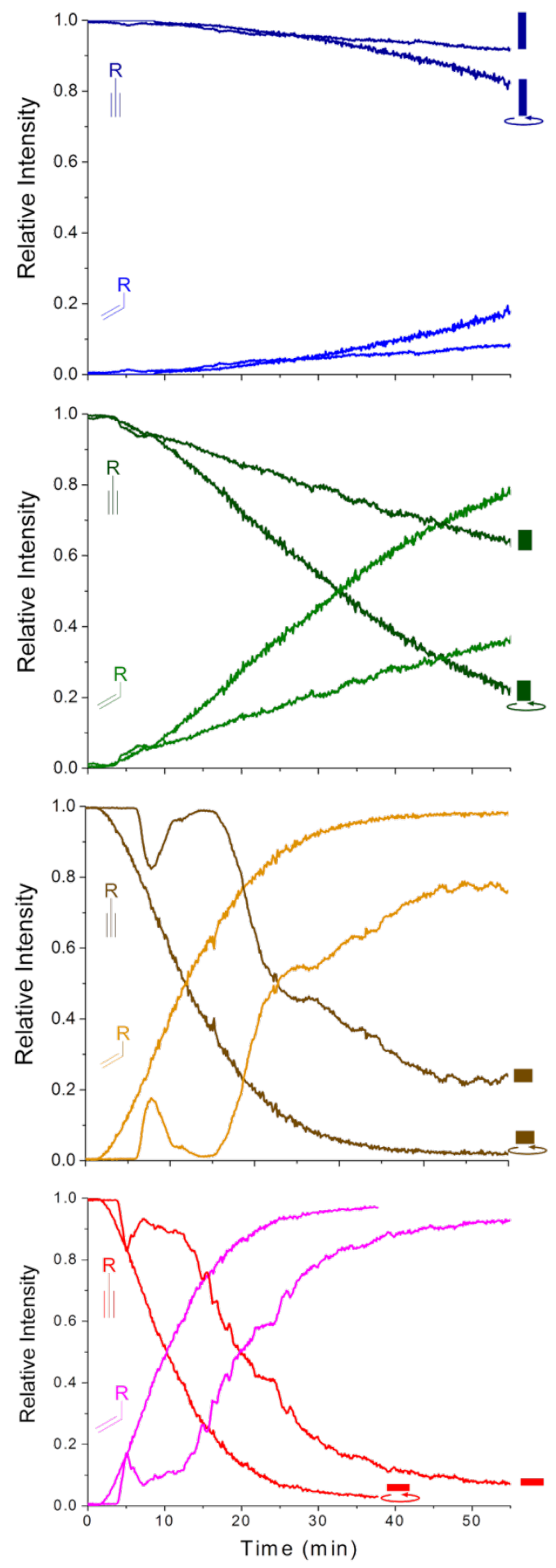

Figure 7. $10 \%$ catalyst loading, 2 equivalents of $\mathrm{H}_{2}$. Comparing reaction rate run with and without stirring in each vial. From top to bottom: V1, V2, V3 and V4. 


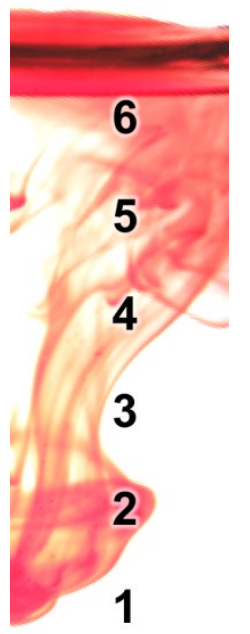

Figure 8. Cartoon of a gas/liquid interface (top gas, bottom solution) with different possible sampling points (1-6) that will give different measurements at the same time point.

\section{Modelling}

We decided to put the interpretation of the experimental observations on a firmer footing by conducting modelling studies. These would be useful not only to confirm that the assumptions made are valid but also because the model would be applicable to other reaction conditions, enabling straightforward selection of appropriate parameters, such as picking a minimum flask diameter for given concentrations of substrates at a particular catalyst loading.

We first note that diffusion of hydrogen in solution is too slow to play any significant role in the mass transport here. The diffusivity of hydrogen in fluorobenzene may be estimated at $D=$ $7 \times 10^{-9} \mathrm{~m}^{2} \mathrm{~s}^{-1}$ (from the diffusivity in water scaled by the ratio of the viscosities), which means the time to diffuse $1 \mathrm{~cm}$ is about $\left(1 \mathrm{~cm}^{2}\right)^{2} / D=4$ hours. This is much longer than the reaction timescale and long enough for convection effects to dominate mass transport in solution. For a stirred solution we may therefore expect the concentrations of hydrogen in the gas and solution to be uniform throughout their respective phases, and this leads to a simple kinetic model in which the transfer of hydrogen across the gas/solution interface may be treated explicitly (Eqs. (1) and (2)). 


$$
\begin{aligned}
& \mathrm{H}_{2}(\mathrm{~g}) \underset{k_{\mathrm{b}}}{\stackrel{k_{\mathrm{f}}}{\rightleftarrows}} \mathrm{H}_{2}(\text { soln }) \\
& \mathrm{H}_{2}(\text { soln })+\text { alkyne } \stackrel{k}{\stackrel{-\rightarrow}{\text { catalyst }}} \text { alkene }
\end{aligned}
$$

The rate of transfer of hydrogen across the gas-liquid interface in $\mathrm{mol} \mathrm{s}^{-1}$ is expected to be proportional to the interfacial area $A$ and the concentration of hydrogen. The net flux into the solution, $J\left(\mathrm{~mol} \mathrm{~m}^{-2} \mathrm{~s}^{-1}\right)$ is given by Eq. (3), where the rate constants $k_{\mathrm{f}}$ and $k_{\mathrm{b}}$ have units $\mathrm{m} \mathrm{s}^{-1}$.

$$
\begin{aligned}
& J=k_{\mathrm{f}}\left[\mathrm{H}_{2}(\mathrm{~g})\right]-k_{\mathrm{b}}\left[\mathrm{H}_{2}(\mathrm{soln})\right] \\
& K=\frac{\left[\mathrm{H}_{2}(\mathrm{soln})\right]}{\left[\mathrm{H}_{2}(\mathrm{~g})\right]}=\frac{k_{\mathrm{f}}}{k_{\mathrm{b}}}
\end{aligned}
$$

The equilibrium constant $K$ (Ostwald coefficient) for this reaction, Eq. (4), may be estimated as 0.0974 from the Henry's law estimate for hydrogen in fluorobenzene, ${ }^{17}$ i.e., the solution concentration at equilibrium is about $10 \%$ of the concentration in the gas phase. The catalytic reaction is known to be first order in catalyst and hydrogen, and zero order in alkyne, ${ }^{10}$ Eq. (5),

$$
-\mathrm{d}[\text { alkyne }] / \mathrm{dt}=k[\text { cat }]\left[\mathrm{H}_{2}(\text { soln })\right]=\mathrm{k}^{\prime}\left[\mathrm{H}_{2}(\text { soln })\right]
$$

where the pseudo-first-order rate constant $k^{\prime}$ is defined in terms of the solution concentration of hydrogen. We now define an apparent concentration of gas-phase hydrogen, Eq. (6), which is the concentration the gas-phase hydrogen would have if it were in the solution volume $V_{1}$.

$$
\left[\mathrm{H}_{2}(\mathrm{~g})\right]^{\prime}=\left[\mathrm{H}_{2}(\mathrm{~g})\right]\left(V_{\mathrm{g}} / V_{\mathrm{l}}\right)
$$

We also define apparent rate constants $k_{\mathrm{f}}{ }^{\prime}$ and $k_{\mathrm{b}}{ }^{\prime}\left(\mathrm{s}^{-1}\right)$ for the hydrogen transfer, Eq. (7),

$$
k_{\mathrm{f}}^{\prime}=k_{\mathrm{f}} A / V_{\mathrm{g}}, k_{\mathrm{b}}^{\prime}=k_{\mathrm{b}} A / V_{1}
$$

Using the apparent concentration and the primed rate constants, the problem is formally identical to classic $\mathrm{A} \rightleftarrows \mathrm{B} \rightarrow \mathrm{C}$ kinetics. The exact solution involves two exponentials with time constants that are complicated functions of the rate constants, ${ }^{20}$ but through Eq. (7) the dependence on the gas-solution interfacial area is explicit. 
The parameters $V_{\mathrm{g}}, V_{1}$ and $A$ are known from the experimental arrangement. In the case of $A$, the internal cross-section of the vial was adjusted for the curved surface of the meniscus, ${ }^{21}$ and the cross-sectional area of the outlet tube was subtracted. The meniscus correction for the tube was assumed to be negligible. These geometric parameters were fixed, and then the expression for the concentration of product alkene as a function of time depends on three unknown parameters: $k_{\mathrm{f}}$, $k_{\mathrm{b}}$ and $k^{\prime}$. These were found by minimising the global sum of squares for the four data sets of Fig. 2, with the result $k_{\mathrm{f}}=0.028 \mathrm{~cm} \mathrm{~min}^{-1} k_{\mathrm{b}} \approx 0, k^{\prime}=0.57 \mathrm{~min}^{-1}$. If $k_{\mathrm{b}}$ is fixed at 0.29 , consistent with the estimated equilibrium constant, then the fitted $k_{\mathrm{f}}$ is insignifcantly changed but $k^{\prime}=9.3$ $\min ^{-1}$ (i.e. $k_{\mathrm{f}}$ is reliably determined by the fit, but $k^{\prime}$ is not). The reaction rate $k^{\prime}$ is sufficiently larger than $k_{\mathrm{f}}$ and $k_{\mathrm{b}}$ that the reaction consumes hydrogen immediately it enters the solution and maintains its solution concentration close to zero. The reaction rate determines the initial upward curvature seen in the first $5 \mathrm{~min}$, but for most of the time the rate is largely determined by mass transfer into the solution. The steady-state approximation then applies to solution hydrogen and the product concentration rises exponentially with rate constant $k_{\mathrm{obs}}=k_{\mathrm{f}}{ }^{\prime} k^{\prime} /\left(k^{\prime}+k_{\mathrm{b}}{ }^{\prime}\right) \approx k_{\mathrm{f}}{ }^{\prime}$. That is, the rate is limited by hydrogen transfer from the gas phase into the liquid phase, and only the rate constant for this is reliably determined by this method.

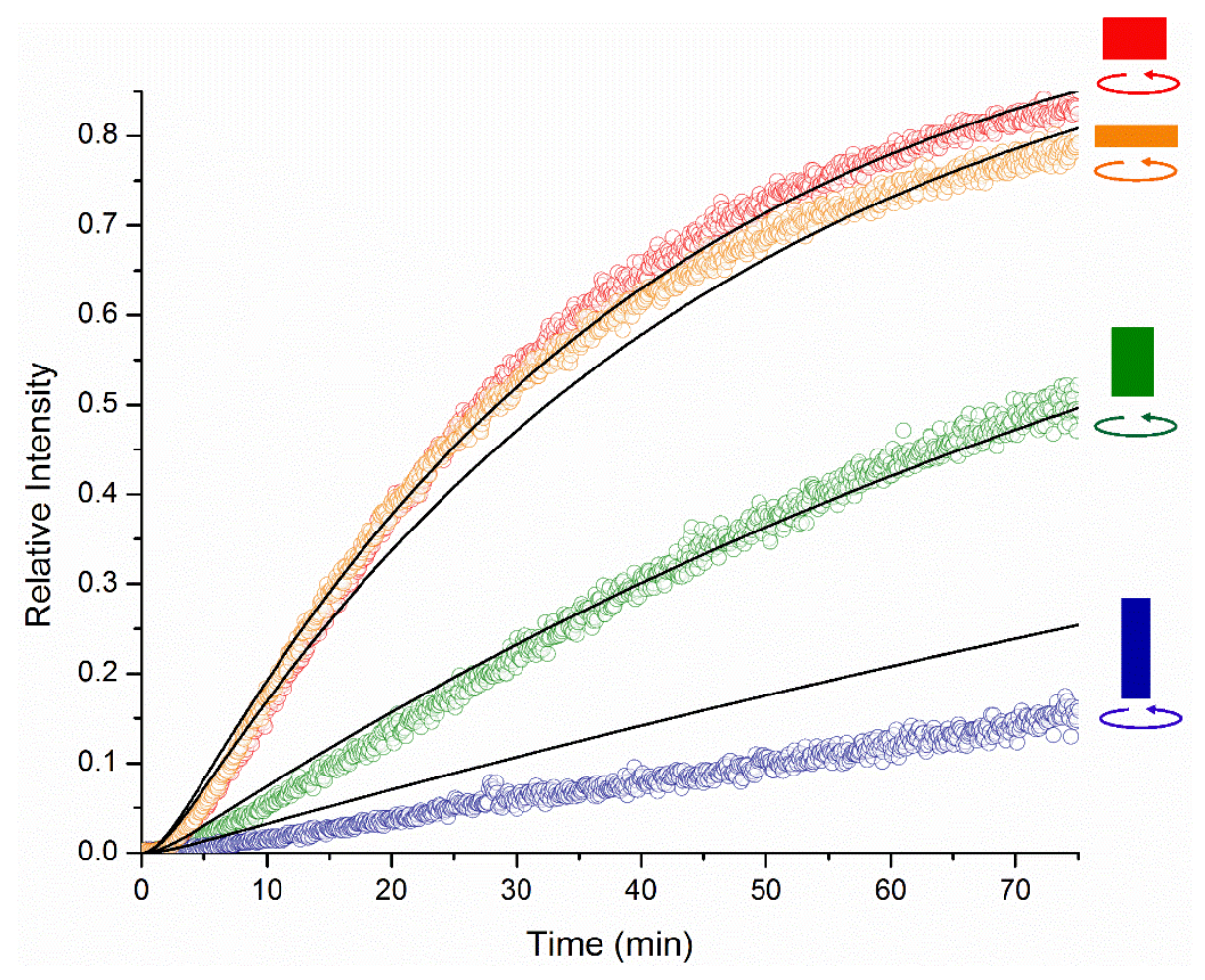


Figure 9. Model compared to experiment for one equivalent of hydrogen, stirred, $10 \%$ catalyst loading, $k_{\mathrm{f}}=0.028 \mathrm{~cm} \mathrm{~min}^{-1} k_{\mathrm{b}}=10^{-11} \mathrm{~cm} \mathrm{~min}^{-1} k^{\prime}=0.57 \mathrm{~min}^{-1}$.

The model predicts that in this regime the rate depends on $A / V_{\mathrm{g}}$ (Eq. (7)). Although $\mathrm{V} 4$ has higher interfacial area, the ratio $A / V_{\mathrm{g}}$ for $\mathrm{V} 3$ and $\mathrm{V} 4$ differ only by $\sim 10 \%$, so that these Vials are much closer than might be expected. Note that the least well-fitted data is for the slowest reaction (V1), and it is slower than expected. This behavior is something we frequently see for slow reactions and/or low catalyst loadings, ${ }^{8}$ because decomposition reactions reduce the effective concentration of active catalyst (both via low, fixed levels of impurities, and increased time available for decomposition).

This simple model qualitatively fits the other data sets where the catalyst loading is doubled and the hydrogen concentration is doubled. Doubling the catalyst loading should double $k^{\prime}$ (Figure 5). Visually, the initiation is faster, but since $k^{\prime}$ is poorly determined it is hard to quantitatively verify this. The rate constant $k_{\mathrm{f}}$ should not change, and this is approximately the case. Doubling the hydrogen concentration (Figure 6) should speed up the reaction by a factor of two, but the rate constants should be unchanged. When two equivalents of $\mathrm{H}_{2}$ are used the reaction should abruptly stop when the alkyne is depleted. This will only be true if the reaction is truly zero order in alkyne. To account for this, the data were only fitted to $90 \%$ conversion. The fitted $k_{\mathrm{f}}$ was found to be similar to the case for one equivalent of hydrogen.

The fitting is very successful, given the simplicity of the model. The model could be improved by including more detailed aspects of the catalyst kinetics or adding convection explicitly, but the fit quality is likely limited by experimental aspects. Catalyst decomposition is likely to be the primary culprit as far as poor fitting is concerned. At the low catalyst concentrations used, even trace amounts of air/moisture/impurities can deactivate the catalyst. Smaller effects may include the assumption of zero order in alkyne, poorly defined $t=0$ time (there is a lag between $\mathrm{H}_{2}$ injection and reaction initiation associated with the time taken for the solution to be pumped into the mass spectrometer, which will depend on the exact flow rate and which may vary by \pm 10 s), normalization to sum of alkene + alkyne masses only, solution depletion in the longer experiments (in an experiment lasting 60 minutes at a flow rate of $20 \mu 1 /$ minute, $12 \%$ of the solution will be consumed (and the headspace will increase in volume accordingly).

\section{Conclusions}


Well-stirred reactions in flasks with a large solution surface area exposed to a reacting gas are limited principally by the low concentration of the gas than by the rate at which the gas migrates into solution. However, as flasks become narrower and especially when they are unstirred, mass transport effects can become significant. Poor mixing results in complex discrepancies from ideal behavior. Convection effects become readily apparent in the experimental data obtained from unstirred vessels via mass spectrometry because of the highly localized sampling. These factors should be carefully considered in reactions involving narrow reaction flasks, especially when unstirred.

\section{Acknowledgements}

JSM and DAH thank NSERC for Discovery Grant funding. JSM also thanks NSERC for Discovery Accelerator Supplement operational funding and CFI, BCKDF and the University of Victoria for infrastructural support.

\section{References}

${ }^{1}$ R. B. Jordan, Reaction Mechanisms of Inorganic and Organometallic Systems, $3^{\text {rd }}$ Ed., Oxford University Press, Oxford, 2007, p 391.

${ }^{2}$ G. Garland, Transport Effects in Homogeneous Catalysis. In The Encyclopedia of Catalysis; Horvath, I. T., Ed.; John Wiley \& Sons, Inc.: Hoboken, 2002; Vol. 6, p 550.

${ }^{3}$ A. Deimling, B. M. Karandikar, Y. T. Shah and N. L. Carr, Chem. Eng. J., 1984, 29, 127.

${ }_{5}^{4}$ S. S. Tamhankar and R. V. Chaudhari, Ind. Eng. Chem. Fundam., 1979, 18, 406.

${ }^{5}$ N. J. Beach, S. M. Knapp, C. R. Landis, Rev. Sci. Instrum. 2015, 86, 104101.

${ }^{6}$ D. G. Vandervelde, J. J. Jonas, Magn. Reson. 1987, 71, 480-484.

${ }^{7}$ A. Torres, N. M. Perez, G. Overend, N. Hodge, B. T. Heaton, J. A. Iggo, J. Satherley, R. Whyman, G. R. Eastham, D. Gobby, ACS Catal., 2012, 2, 2281-2289.

${ }^{8}$ R. Theron, Y. Wu, L. P. E. Yunker, A. V. Hesketh, I. Pernik, A. S. Weller, J. S. McIndoe, $A C S$ Catalysis, 2016, 6911-6917.

9 (a) L. P. E. Yunker, R. L. Stoddard, J. S. McIndoe, J. Mass Spectrom., 2014, 49, 1-8. (b) Z. Ahmadi, A. G. Oliver and J. S. McIndoe, ChemPlusChem, 2013, 78, 632-635.

${ }^{10}$ J. Luo, R. Theron, L. J. Sewell, T. N. Hooper, A. S. Weller, A. G. Oliver, J. S. McIndoe Organometallics, 2015, 34, 3021-3028.

${ }^{11}$ D. M. Chisholm, J. S. McIndoe, Dalton Trans., 2008, 3933-3945.

${ }^{12}$ (a) K. L. Vikse, Z. Ahmadi, C. C. Manning, D. A. Harrington, J. S. McIndoe, Angew. Chem., Int. Ed., 2011, 50, 8304-8306; (b) Z. Ahmadi, J. S. McIndoe, Chem. Commun. 2013, 49, 1148811490 .

${ }^{13}$ J. Luo, A. G. Oliver, J. S. McIndoe, Dalton Trans., 2013, 42, 11312-11318. 
${ }^{14}$ (a) C. R. Landis, J. Halpern, J. Am. Chem. Soc., 1987, 109, 1746-1754. (b) Y. Sun, R. N. Landau, J. Wang, C. LeBlond, D. G. Blackmond, J. Am. Chem. Soc., 1996, 118, 1348-1353.

${ }^{15}$ D. J. Ager, A. H. M. de Vries, J. G. de Vries, Chem. Soc. Rev., 2012, 41, 3340-3380.

${ }^{16}$ E. Brunner, J. Chem. Eng. Data, 1985, 30, 269-273.

${ }^{17}$ N. Bruecki, J. I. Kim, Z. Phys. Chem., 1981, 126, 133-150

${ }^{18}$ Wang, M. E. Goldman, T. J. Emge, A. S. Goldman, J. Organometal. Chem., 1996, 518, 55-68.

${ }^{19}$ (a) K. L. Vikse, M. P. Woods, J. S. McIndoe, Organometallics 2010, 29, 6615-6618. (b) K. L. Vikse, Z. Ahmadi, J. Luo, N. van der Wal, K. Daze, N. Taylor, J. S. McIndoe, Int. J. Mass Spectrom. 2012, 323-324, 8-13.

${ }^{20}$ G. I. Gellene, J. Chem. Ed. 1995, 72, 196.

${ }^{21}$ C. W. N. Cumper, J. Coll. Interf. Sci. 1967, 23, 154. 